\title{
Syntactic Interference: A Study of Ígálá and English Noun Phrases in Malachai 1:6 and Mathew 2:1
}

\author{
Ocheja Theophilus Attabor \\ A Graduate Student of Department of Linguistics, African and European Languages, College of Humanities, \\ Management and Social Sciences, Kwara State University, Malete-Ilorin Nigeria
}

\begin{abstract}
Ígála native speakers face some challenges in their attempt to acquire the English language and one of these challenges is encountered in their attempt to use English Noun Phrases. Learning English Noun Phrases by speakers whose mother-tongue is Ígála is one of the most frequent and significant areas of difficulties at syntactic level which Ígálá learners of English come across due to the differences between the NP systems in both languages. The Ígálá language has an NP system that functions differently, for instance, the notion of definiteness and indefiniteness of articles are encoded differently than in that of the English language. Given the fact that articles are one of the most frequent words occurring in the English language Noun Phrase, this study pinned down such an important issue by describing how the differences between the Ígálá and English languages in concern to the Noun Phrase system cause Igálá learners of English to commit errors (Mother-Tongue interference) in their English learning process as a result of Mother-Tongue illiteracy, incompetence in both L1 and L2, and inconsistencies in Ígálá articles. This work was anchored on PSG and labelled brackets as a model of syntactic analysis. The paper made use of bilingual text approach. The work observed that there is direct transfer of the grammatical features of Ígálá to English language and that there is positive transfer of linguistic features from Ígálá to English where there are linguistic similarities between the two languages. The paper also observed that possessive adjectives (his, my, your, her) pose no problem for Ígálá learners of English. The paper concluded by saying that the problems Ígálá L1 speakers encounter while attempting to use English Noun Phrases are based not only on the degree of differences between the Ígálá and English Noun Phrase systems, but inconsistencies in Ígálá articles.
\end{abstract}

Keywords: Second Language, Noun Phrase, Interference.

DOI: $10.7176 / J L L L / 60-06$

Publication date:September $30^{\text {th }} 2019$

\section{Introduction}

Interference, also known as cross linguistic influence refers to speakers or writers applying knowledge from one language (Igala) to another language (English). It is the transfer of linguistic features between languages in the speech repertoire of a bilingual individual, whether from first language to second language or from second language to first or many other codes. It is most commonly discussed in the context of English language learning and teaching, but it can occur in any situation when someone does not have a native-level command of a language, as when translating into a second language.

Learners of English, despite their different backgrounds, face difficulties when it comes to learning English as a second or foreign language. Ígálá native speakers of English for instance encounter shared difficulties at the level of using English Noun Phrases as a result of the nature of the Ígálá Noun Phrase systems and its influence on English learning. Consequently, Mother-tongue interference, which is the effect of the learners' native language on second language learning becomes prevalent. Therefore, the Ígálá language interferes with the learning of English language, especially while using English Noun Phrases. This is to say that due to the differences between the İgálá and English Noun Phrase systems, transfer of L1 features into L2 is bound to take place. Thus, this paper explains these problems and recommends possible solutions in order to improve the competence and performance of non-native users of English, especially Ígálá speakers.

\subsection{Review of Related Literature}

A phrase is a word or a string of words that forms a grammatical unit within a sentence. Burton-Roberts (1986) defines a phrase as "a sequence of words that can function as a constituent in the structure of sentences" (p.19). Many constituents are used for the formation of a sentence but Noun Phrase is very common cross-linguistically. It is the main construction which can be the object, subject or complement of a clause; it must contain a noun or noun-like word (pronoun) as the main element called the head. It may contain other elements, either before or after the head. In the words of Omachonu (2011), "the Noun Phrase is the most important or basic syntactic category attested in all languages" (p.141). This means that it is syntactically important because it plays roles like those of nouns. Structurally, a Noun Phrase is the largest expansion of the maximal projection of the noun.

Kroeger (2005) avers that a noun phrase "is a phrasal constituent whose head is a noun'. He further states that 'NPs in English, and most other languages, can function as subjects, primary or secondary objects, and 
objects of preposition" (p.87). This implies that a noun phrase contains, and is centred on a noun. For instance, the hot tasty currant bun is a Noun Phrase and it contains the noun "buns" as the main constituent. Why does the phrase as a whole have to be the same category as the word buns? The reason is that buns functions as the main element of the Noun Phrase or, as Mbah (2016) and Mathews (2003) would call it, the head of the Noun Phrase. A Noun Phrase may contain more than one noun, but only one noun in a Noun Phrase can function as its head. The distinction between the head and the remaining elements of the Noun Phrase is that the head noun is obligatory while the other elements are optional. Besides, when we say that a Noun Phrase consists of a head noun and other secondary elements and that the secondary elements are typically optional, it automatically follows that a noun phrase can consist just of a head noun.

Traditionally, a phrase is understood to contain two or more words. The traditional progression in the size of syntactic units is word, phrase, clause, and in this approach a single word (such as a noun or pronoun) would not be referred to as a phrase. However, many modern schools of Syntax, especially those that have been influenced by the X-bar theory make no such restriction. Here many single words are judged to be phrases based on a desire for theory-internal consistency. A noun phrase is deemed to be a word or a combination of words that appears in a set syntactic position, for instance in subject position or object position.

\subsection{Contrastive Analysis}

Contrastive Analysis has been the first major theory dealing with the relationship between the languages a learner acquires. Linguists have always been interested in comparing and contrasting different language systems and the pioneering works appeared at the end of the nineteenth century (James, 1981). The term 'Contrastive Study' was coined by Whorf (1941); before then this discipline had been called 'Comparative Linguistics' or 'Comparative Studies' (Fisiak, 1981). After the World War II, the interest in teaching foreign languages increased in the USA and many linguists were concerned with pedagogically oriented contrastive studies, especially in trying to predict learning difficulties on the basis of comparing the native language with the foreign language being learnt, and also with the study of bilingualism and language contact phenomena. It was believed that pointing to the similarities of the two languages compared will make the process of foreign language learning easier for the learner. Robert Lado's formulation of the 'Contrastive Analysis Hypothesis' in his Linguistics Across Cultures (1957) is considered the greatest contribution in the field of contrastive studies (Fisiak 1981, James 1981 and Krzeszowski 1990).

\subsection{Division of Contrastive Studies}

Fisiak (1981) divides contrastive studies into theoretical and applied. "Theoretical contrastive studies give an exhaustive account of the differences and similarities between two or more languages". He further states that theoretical contrastive studies provides "an adequate model for the comparison, and determine how and which elements are comparable ..." (pp. 2-3). They are language independent, which means that they do not investigate how a particular category or item present in language A is presented in language B, but "they look for the realization of a universal category X in both A and B" (Fisiak, 1981, p. 2). But Applied contrastive studies belong to applied linguistics. Fisiak (1981, p. 2-3) explains that "drawing on the findings of theoretical contrastive studies they provide a framework for the comparison of languages, selecting whatever information is necessary for a specific purpose ...". The main focus of applied contrastive studies is "the problem of how a universal category $\mathrm{X}$, realized in language $\mathrm{A}$ as $\mathrm{Y}$, is rendered in language $\mathrm{B}$, and what may be the possible consequence on this for a field of application" (Fisiak 1981, pp. 2-3). They are also concerned with "the identification of probable areas of difficulty in another language where, for example, a given category is not represented in the surface and interference is likely to occur" (Fisiak, 1981, p. 3). So they are rather interested in the surface representation of language. Being a part of applied linguistics; applied contrastive studies depend on several other disciplines, including theoretical, descriptive and comparative linguistics, psycholinguistics, sociolinguistics, didactics and psychology of learning and teaching (Krzeszowski, 1990).

\subsection{Formulating Contrastive Analysis Hypothesis}

The Contrastive Analysis Hypothesis (CAH) was widely accepted in the 1950s and 1960s USA and its original purpose was purely pedagogical. The teaching method which used the $\mathrm{CAH}$ as its theory of learning was the audiolingual method. Based on behaviorist and structuralist theories, the basic assumption for this hypothesis was that "the principal barrier to second language acquisition is the interference of the first language system with the second language system ..." and "... that second language learning basically involved the overcoming of the differences between the two linguistic systems - the native and target languages" (Brown, 1980, p. 148). The term 'interference' here refers to "any influence from the L1 which would have an effect on the acquisition of L2" (Powell, 1998, p. 2).

The assumptions about L1 interference were supported by the evidence from speakers' performance in their second language. As Brown (1980) states, "it is quite common, for example, to detect certain foreign accents and 
to be able to infer, from the speech of the learner alone, where the learner comes from" (p. 149). Lado's practical findings were based on his own experience and family background. Being an immigrant to the USA and a native speaker of Spanish, he observed what difficulties his Spanish-speaking parents had with learning English and how interference was evident in their speech. In the preface to Linguistics across Cultures, Robert Lado explains:

The plan of this book rests on the assumption that we can predict and describe the patterns that will cause difficulty in learning, and those that will not cause difficulty, by comparing systematically the language and the culture to be learned with the native language and culture of the student (Lado, 1957, p. vii cited in Brown, 1980, p. 149).

Later in the same book he claims that:

The student who comes in contact with a foreign language will find some features of it quite easy and others extremely difficult. Those elements that are similar to his native language will be simple for him, and those elements that are different will be difficult. The teacher who has made a comparison of a foreign language with the native language of the student will know better what the real learning problems are and can better provide for teaching them, (Lado, 1957, p. 2 cited in Fisiak, 1981, p. 4).

This formulation of the Contrastive Analysis Hypothesis was later called by Ronald Wardhaugh 'the strong version' of the Contrastive Analysis Hypothesis (Brown 1980, p. 157). Another linguist supporting the strong version of the $\mathrm{CAH}$ was Fries. In his opinion, "the most effective [teaching] materials are those that are based upon a scientific description of the language to be learned, carefully compared with parallel description of the native language of the learner" (Fries, 1945, p. 9 cited in Powell, 1998, p. 1). Wardhaugh believes that the strong version was "unrealistic and impracticable", since "at the very least, this version demands of linguists that they have available a set of linguistic universals formulated within a comprehensive linguistic theory which deals adequately with Syntax, Semantics, and Phonology" (Wardhaugh, 1970, p. 125 cited in Brown, 1980, p. 157).

\section{The Linguistic Classification of the Ígálá Language}

Ígálá is of the Kwa branch of the Niger-Kordofanian (Adegbija, 2004, p.46). African languages (excepting creoles, pidgin, and 'official' languages which were inherited from the colonial era) fall under four major language families: Niger-Congo, Nilo-Saharan, Afro-Asiatic, and Khoisan. However, Niger-Congo, to which Kwa belongs, is the largest of all whether in terms of the number of languages under it or in terms of the geographic spread (Bendor-Samuel 2006, p.768). The Kwa languages are spoken in West Africa and they are a branch of the Niger-Congo family which extends from "Southeastern Ivory Coast in the west through the southern two-thirds of Ghana, southern Togo, and the Republic of Benin to Benin-Nigeria border in the east...in all Kwa languages, the fundamental word order is subject-verb-object" (Dakubu 2006, pp. 630-632). Recent research shows that Ígálá is a member of the Benue-Congo (New Benue-Congo) branch of language within the Niger-Congo. Benue-Congo languages form a very large group in Africa including the Bantu languages. Williamson (2006, p. 150) confirmed that "the term 'Benue-Congo' was introduced by Greenberg (1963) to refer to one of the six branches of his Niger-Congo family." Greenberg (1963) contrasted Benue-Congo with the other branches of Niger-Congo and discovered it was particularly close to Kwa. So in the late twentieth century, Kwa was split in half and the eastern half was combined with Benue-Congo resulting in such classifications as Western Benue-Congo (former Eastern Kwa where Ígálá belonged) and Eastern Benue-Congo (old BenueCongo), Bennett and Sterk (1997), Bendor-Samuel (1959), Blench (1989).

\subsection{Theoretical Framework}

This work is anchored on Phrase Structure Grammar (PSG henceforth). PSG is a grammar that analyses utterances according to their syntactic constituents. It "states the linear organization of the constituents of an utterance" (Lamidi, 2008, p.66). Its main objective is to describe the present state of an utterance without making any statement about how it is derived. Re-write rule is used in PSG to guide the linguist in his analysis of utterances. The rule states that a sentence $\mathrm{S}$ is to be factorised as $\mathrm{S} \rightarrow \mathrm{NP}$ AUX VP (ADJUNCT). This means that a sentence is to be decomposed as NP AUX VP (ADJUNCT). Adjunct is placed in brackets to indicate that it is optional. According to Omachonu (2011, p.177), "the publication in 1957 of Chomsky's Syntactic Structures (SS) marks the formal beginning of the Phrase Structure Grammar." PSG according to Agbedo (2000) is a rewrite grammar which aims at providing the mechanism for splitting up a given sentential structure into its constituents beginning with the immediate constituents. PSG negates IC structuralists' position or assertion that a sentence consists of only two constituents. The basic assumption of PSG is that any sentence that falls outside the structure NP AUX VP (ADJUNCT) is ungrammatical, therefore not generable and this indicates its weakness as there are many well-formed acceptable sentences that fall outside the structure prescribed by PSG.

\subsection{Methodology}

The method of data collection is bilingual text approach using Bible in English and Ígálá expression. Out of 
many versions of the Bible in English expression, we chose the Revised Standard Version because it is the approved version by examination bodies like WAEC, NECO, NABTEB and JAMB, and the Bible in Ígálá expression because it is the only widely used written text by native speakers. Biblical text is considered appropriate due to lack of texts in Ígálá expression (e.g. Quran, literary texts of any genre-prose, drama and poetry by any writer). Apart from Primers (which are very elementary), Bible in Ígálá expression remains a reliable source of data because it is not amenable to everyday inflection. Besides, owing to the pervasive level of mother-tongue illiteracy, textual method is preferred over oral method for objectivity. The chosen data were illustrated and analysed using the PSG and labelled brackets in order to clearly show the structures of the NPs being analysed. Two sample data drawn from Malachi 1:6 and Mathew 2:1 were analysed in labelled brackets model of syntactic analysis. Data 1 contains 11 NPs in English and Ígálá which were compared in order to arrive at areas of difficulty for the learners.

\subsection{Discussion}

Example 1

Source: Malachi 1:6

English: [A son honours his father and a servant his master. If then I am a father, where is my honour? And if I am a master, where is my fear? says the Lord of host to you, $\mathrm{O}$ priests, who despise my name. You say, 'How have we despised your name?]

Ígálá: [Oma adojima n̆w ata-wn̆, adu la ache $\breve{n} w$ odu-wn̆ $;$ mak ichewn̆ k'omi ch'ata one, ugbo ojima-mi dẹke? Ila chẹwn k'omi ch'odu, ugbo ailo-mi ku maradẹ? Jihofa ki n'ewn̆ du akola n̆wu me, ame amatama, ku me d'odu-mi r'ibete. Ŏn me kakini, ugbo on̆ awa d'odu-we r'ibete ke?]

The Labelled Brackets Analysis of the NPs in English and Ígálá in Malachi 1:6

\begin{tabular}{|c|c|c|c|c|}
\hline & English & Phrasal Analysis & Ígálá & Phrasal Analysis \\
\hline 1 & A son & {$[\mathrm{NP}[\mathrm{Det} \mathrm{a}][\mathrm{N}$ Son $]]$} & Oma & {$[\mathrm{NP}[\mathrm{N}$ OMa $]$} \\
\hline 2 & His father & [NP [Det (poss. adj.) his ] [N father]] & Ata-wn & [NP [N ata] [Det (poss. Adj.)Wñ]] \\
\hline 3 & A servant & [NP [Det a] [N servant] & $\mathrm{Adu}$ & {$[\mathrm{NP}[\mathrm{N}$ adu $]]$} \\
\hline 4 & His master & [NP [Det (poss. adj.) his] [N master]] & Odu-wn & [NP [N odu] [Det (poss. Adj.)Wñ $]]$ \\
\hline 5 & A father & [NP [Det a] [N father]] & Ata & [NP [N ata]] \\
\hline 6 & My honour & [NP [Det (poss. adj) my] [N honour]] & Ojima mi & [NP [N Ojima] [Det (poss. Adj.) mi]] \\
\hline 7 & A master & {$[\mathrm{NP}[\mathrm{Det} \mathrm{a}][\mathrm{NOdu}]]$} & Odu & {$[\mathrm{NP}[\mathrm{N}$ odu $]]$} \\
\hline 8 & My fear & {$[\mathrm{NP}[$ Det (poss. adj) $\mathrm{my}][\mathrm{N}$ fear $]]$} & Ailo mi & [NP [N ailo] [Det (poss. Adj.) mi]] \\
\hline 9 & The lord of host & [NP [Det the $][\mathrm{N}$ lord] [pp [p of] [N host]]] & Jihofa & [NP [N Jihofa] \\
\hline 10 & My name & {$[\mathrm{NP}[$ Det (poss. adj) $\mathrm{my}][\mathrm{N}$ name $]]$} & Odu-mi & [NP [N odu] [Det (poss. Adj.) mi]] \\
\hline 11 & Your name & [NP [Det (poss. Adj.) your] [N name]] & Odu wẹ & [NP [N odu] [Det (poss. Adj.) wẹ]] \\
\hline
\end{tabular}

A look at the phrase above shows that there are eleven groups of Noun Phrase with four groups preceded by the indefinite article $a$ : [a son, a servant, a father, and a master], one group preceded with definite article: [the Lord] and six other groups of NP structures with possessive adjectives as determiners: [his father, his master, my honour, my fear, my name and your name]; and out of the four Noun Phrases with the article $a$, the analogous NPs in Ígálá are structured with the article omitted while the analogous NPs in Ígálá for those with possessive adjectives as determiners are structured accordingly (although while in English the possessive adjectives premodify the head, the reverse is the case in Ígálá). Yet the analogous NP in Ígálá for the group with definite article is without lę-the. This shows the rate of inconsistency in the use of articles in Ígálá.

The underscored structures in English and Ígálá are consistent in the use of possessive adjectives as determiners to pre-modify (English) and post-modify (Ígálá) their nominal heads. The overt difference between the English and Ígálá NP structures here is in the location of the head, while English is head-final, Ígálá is headinitial and that is what Ígálá users of English simply need to learn. This may cause little or no problem for Ígálá users of English since the same features found in Ígálá Noun Phrase structures are also present in the analogous English Noun Phrase structures as in serial number 2, 4, 6, 8, 10 and 11 on the table above.

On the contrary, the structures in bold, in English and Ígála reveal a case of inconsistency in the use of articles in Ígálá. A common error arises for Ígálá speakers to structure English sentences without articles owing to wide spread of inconsistency in the use of articles observed in the Noun Phrase structures of Ígálá as shown in serial number 1, 3, 5, 7 and 9. above. However, language interference is most often discussed as a source of errors known as negative transfer, which occurs when speakers and writers transfer items and structures that are not the same in both languages. Within the theory of contrastive analysis, the systematic study of a pair of languages with a view to identifying their structural differences and similarities, the greater the differences between the two languages, the more negative transfer can be expected. For example, since Ígálá has no separate demonstratives denoting singularity and plurality, Ígálá users of English are likely to use either of the 
demonstratives this/these for all kinds of subjects in actual performance eg (a) this men (b) these man thereby committing the error naturally based on the internal structures of Igala. Therefore, an aspect where Ígálá users of English will encounter some problems is in the use of determiners, especially definite and indefinite articles looking at their distributions within the NP structures of both languages.

However, when the relevant unit or structure of both languages is the same, interference can result in correct language production called positive transfer because the right structure is in line with most native speakers' notions of acceptability. An example is when possessive adjectives (his, your, my, our, their) precede nominal items in English, Ígálá users of English do not face much problem in using them apart from the location of the head, since possessive adjectives as mentioned above are evenly represented in English and Ígálá and they are consistently used.

Example 2

Source: Mathew2:1

English: "Now when Jesus was born in Bethlehem of Judea in the days of Herod the king, behold wise men from the East came to Jerusalem, saying"

Ígálá:“'On̆abuku ma fi Jisus bi Bethlehem e-Judia ôkpanachi onu Herod, mẹ go amakuli kw’ olodudu lewa Jerusalem, ma kakini,"

In data 2 , the adjective wise which qualifies the noun men in the phrase wise men from the east is embedded in the head-word in Ígálá such that wise men become a singular word in Ígálá as presented below:

English:[ NP [Adj Wise] [N men] [pp [p from] [NP[Det the][N east]]]]

Ígálá: [NP [N Amakuli] [pp kw'][n olodudu]]]

This implies that the sense of wisdom, gender, and number in the phrase is subsumed in one single word in Ígálá, thus Ígálá speaker users of English are likely to transfer this feature into English as [NP][N amakuli]. A look at the phrase wise men from the east (amakuli kw'olodudu) shows it has the component $\mathbf{A d j}+\mathbf{N}+\mathbf{P P}+\mathbf{N P}$ in English while in Ígálá it is $\mathbf{N}+\mathbf{P P}$. ESL users have no problem with the Prepositional component of the phrase, rather they have problems with the Noun phrase part (wise men) which in Ígálá denotes a singular word, and by implication, the sense of wisdom, gender, and number has been subsumed in one single word in Ígálá and learners are likely to transfer this feature into the Target language in the course of learning. This can create transfer problems for a second language user who may attempt to produce a noun phrase whose maximal projection is a non-branching node with a path leading directly to the noun. In this case the node labelled NP will immediately dominate the noun instead of dominating the noun exhaustively. Consequently, the second language user is hereby faced with the problem of over-generalisation of the rule by being ignorant of the rule of L2 in terms of lexical and syntactic structures. By extension, the ill-formed word 'wisemen' emerges as learners attempt to form a Noun Phrase in English from their linguistic background where 'amakuli' is a single word.

Competence in English is all inclusive, so the appropriate combination of lexical items in their respective constituents within NPs by second language users of English is a mark of productive learning. Consequently, the differences between English and Ígálá noun phrases can pose some problems such as transfer to second language learning. Transfer of First language (L1) features/grammatical system to the Second Language (L2) is one of the problems associated with second language learning. Language transfer, also known as L1 interference, refers to speakers or writers applying knowledge from one language to another language. It is the transfer of linguistic features between languages in the speech repertoire of a bilingual or multilingual individual, whether from first to second, second to first or many other relationships. It is most commonly discussed in the context of language learning and teaching, but it can occur in any situation when someone does not have a native-level command of a language, as when translation into a second language is done. Naturally, learners have the tendency to unconsciously transfer the system of first language (L1) to the second language (L2) during second language acquisition because the assumption is that the knowledge of L1 will affect the learning of L2. Contrastive analysis operates on the principle that second language (L2) learners tend to transfer to their (L2) production (utterances) formal features of their (L1). Lado has explained that:

Individuals tend to transfer to the forms and meanings, and the distribution of forms and meanings of their native language and culture both productively when attempting to speak the language and to act in the culture, and receptively when attempting to grasp and understand the language and the culture as practised by natives (Lado 1957, p.2)

\subsection{Findings}

One of the factors of syntactic interference from Ígálá to English as shown by this study is inconsistency in Ígálá system of articles within an NP. Consequently, Ígálá speakers structure sentences in English thereby omitting the articles owing to wide spread inconsistency in the distribution of articles in Ígálá.

\subsection{Recommendation}

The pervasive level of Mother Tongue illiteracy should be dealt with. The truth is that a lot of people are 
proficient in speaking their Mother Tongue and can do next to nothing in the writing and reading of the language. Literacy in Mother Tongue is indeed a good booster for the appropriate learning of a Target Language, particularly English.

Mother-Tongue Interference in the Acquisition of English Noun Phrases by L1 Ígálá speakers can be resolved by the teacher's mastery of the two codes (English and Ígálá). This will enhance the teaching and learning of the Target language. This can better be explained within the context of the key role of bilingualism in the Target Language (TL) teaching context within Second Language Acquisition. Since no code can be deactivated in this context, a teacher's grasp of both can do the learning process a great deal of good. Most especially in the area of syntax, interference is very evident among bilinguals. The teacher's sufficient mastery of the Ígálá and the English languages will help the teacher to understand some of the interference errors that can occur in the learners' use of the language and to be able to guide the learners to avoid them. This then shows that the teacher's mastery of both codes enhances the teacher's efficiency in grounding the students in the appropriate rules and use of the target language, (English).

Both the teachers and the learners should be made to be aware of the basic problem areas resulting from the difference in the syntactic structures of the two languages. This awareness will enable them to isolate areas where emphasis should be laid for effective remediation. The non native users of English (Ígálás) should be encouraged to keep and maintain an Error Gravity Exercise Book where all errors that interfere with English word formation or impede intelligibility during class activities, assignments or discussions are entered into.

\subsection{Conclusion}

In conclusion, when the relevant unit or structure of both languages is the same, interference can result in correct language production called positive transfer because the right structure is in line with most native speakers' notions of acceptability. However, language interference is most often discussed as a source of errors known as negative transfer, which occurs when speakers and writers transfer items and structures that are not the same in both languages. Within the theory of contrastive analysis, the systematic study of a pair of languages with a view to identifying their structural differences and similarities, the greater the differences between the two languages, the more negative transfer can be expected as seen in the example above. The results of positive transfer go largely unnoticed and so are less often discussed. Nonetheless, such results can have a large effect. Generally speaking, the more similar the two languages are and the more the learner is aware of the relation between them, the more positive transfer will occur

Finally, the paper clarifies issues in respect of inconsistencies of articles in Ígálá NPs which constitute errors for Ígálá users of English as a second language. In addition, the study reflects on interference from Ígálá to English owing to some significant syntactic pattern in Ígálá that are not found in English. In conclusion, Noun phrases in English and Ígálá have some syntactically significant differences, especially the environment of occurrence of the head as well as the distribution of articles, which can improve the usage of English by non native speakers, especially Ígálá speakers. Although English and Ígálá have certain similar linguistic features in terms of a finite set of fundamental principles which are universal, the parametric system which determines their syntactic variability differ greatly. A variation in language system is not arbitrary. There are systematic similarities, presumably determined by essential universal human characteristics. And one of the basic aims of Linguistics is to discover uniformities between languages and patterns in rule systems and in doing so; care must be taken not to disregard the uniqueness of any language.

\section{References}

A contrastive analysis of English and Vietnamese noun phrases. www.asha.org/policy. Retrieved from http://wisevn.com/_ed/CA2011/4B-08_chu_van_Binh.pdf retrieved on 17/04/2018.

Adegbija, E. (2004). Mültilingualism: A Nigerian case study. Asmara: Africa World Press Inc.

Agbedo C.U. (2015). General linguistics: Historical and contemporary perspectives. Nsuka: Kumcee-Ntaeshe Press Inc.

Aitchison J. (2001). Cassel's dictionary of English grammar. London: Cassell \& Co.

Bendor-Samuel, J. (2009). Niger-Congo languages. In K. Brown \& S. Ogilvie (eds.). Concise encyclopedia of languages of the world.(pp.768-772). UK: Elservier Ltd.

Burcton-Roberts, N. (1986). Analysing sentences. An introduction to English syntax. London, England: Longman Inc.

Carnie, A. (2007). Syntax: A generative introduction (2nd ed.). USA: Blackwell

Chomsky, N. \& Lasnik, H. (1993). The theory of principles and parameters. In Syntax: an international handbook of contemporary research. von Stechow, J. Jacobs A., Sternefeld, W. \& Vennemann, T. (eds.). Berlin: De Gruyter.

Dakubu, M.E.K. (2009). Kwa languages. In K. Brown \& S. Ogilvie (eds.). Concise encyclopedia of languages of the world (pp.630-633). UK: Elservier Ltd. 
Denzin, N.K. and Lincoln, Y.S (eds.), (1994). Hand book of qualitative research, thousand Oaks, CA: sage publications.

Ellis, R (1994). The study of second language acquisition. Oxford: oxford University Press.

Kroeger, R. P. (2005). Analysing grammar: An introduction. UK: Cambridge University Press.

Lado, R, (1957). Linguistics across cultures: Applied linguistics for language teachers. Ann Arbor: University of Michigan Press.

Lamidi, M.T. (2008). Aspects of chomskyan grammar (Revised ed.). Ibadan: University Press Plc

Mathews P.H. (2003). Linguistics: A very short introduction. New York: Oxford University Press Inc.

Obadan, M.I. (2016). Contrastive analysis. In B.M Mbah (ed.), Theories of linguistics (pp.182-196). Nsuka: University of Nigeria Press Ltd.

Okpanachi, H. (2002) Ùkọchẹ íchi Ígálá: An Ígálá language lesson. Ankpa: Cuca Printers.

Omachonu G.S. (2011a). Ígálá language studies: Progress, issues and challenges. In G.S Omachonu (ed.), Ígálá language studies (pp. 15-45). Germany: Lap Lambert Publishing.

Omachonu G.S. (2011b). Introduction to syntax. In G.S Omachonu (ed.). NSUK texts in general linguistics. 1, Enugu: Rossen publications Ltd.

Weinreich, U. (1968). Languages in contact: Findings and problems. The Hague, The Netherlands: Mouton \& Co.

Williamson, K. (2009). Benue-Congo languages. In K. Brown \& S. Ogilvie (eds.) Concise encyclopedia of languages of the world.(pp.150-152). UK: Elservier Ltd.

https://en.wikipedia.org/wiki/Language_transfer 